Tianhua Ju, Xueyong Ding*, Yingyi Zhang*, Xiangkui Chen, Weiliang Chen, Bo Wang and Xinlin Yan

\title{
Partition Behavior of Alloying Elements in Nickel-Based Alloys and Their Activity Interaction Parameters and Infinite Dilution Activity Coefficients
}

https://doi.org/10.1515/htmp-2018-0120

Received July 22, 2018; accepted November 09, 2018

\begin{abstract}
The partition behavior of alloying elements between the $\gamma^{\prime}$ and $\gamma$ phases in Nickel-based alloys was investigated by using infinite dilution activity coefficient and activity interaction parameter. The results showed that the preferential partition behavior of elements in the $\gamma^{\prime}$ and $\gamma$ phases is related to its infinite dilution activity coefficient $\left(\ln \gamma_{i}^{0}\right)$. When $\ln \gamma_{i}^{0} \ll 0$, the element $\boldsymbol{i}$ has a strong tendency to partition in the $\gamma^{\prime}$ phase; When $\ln \gamma_{i}^{0}$ approaches to zero, the element $\boldsymbol{i}$ has preferentially partition to the matrix $\gamma$ phase. In addition, the partition behavior of element $\boldsymbol{i}$ in the $\gamma^{\prime}$ and $\gamma$ phases is also affected by the third element $\boldsymbol{j}$ in Nickel-based alloys, and this effect can be distinguished by the sign of the second-order activity interaction parameter $\rho_{i}^{i j}$.
\end{abstract}

Keywords: activity interaction parameter, infinite dilution activity coefficient, elemental partition, Nickel-based alloys

\section{Introduction}

Nickel-based alloys have important applications in hightemperature fields as they can offer outstanding properties both in mechanical strength and resistance to surface degradation, even when the environment temperature approaches to $90 \%$ of their melting temperatures [1]. These extraordinary properties largely depend on the

*Corresponding authors: Xueyong Ding, School of Metallurgy, Northeastern University, Shenyang 110004, Liaoning Province, China, E-mail: xyding@mail.neu.edu.cn

Yingyi Zhang, School of Metallurgical Engineering, Anhui University of Technology, Maanshan 243002, Anhui Province, China,

E-mail: zhangyingyi@cqu.edu.cn

Tianhua Ju, School of Metallurgy, Northeastern University, Shenyang 110004, Liaoning Province, China, E-mail: jthua89@gmail.com Xiangkui Chen, Panzhihua University, Panzhihua 617000, China Weiliang Chen, Bo Wang, School of Metallurgy, Northeastern University, Shenyang 110004, Liaoning Province, China Xinlin Yan, Institute of Solid State Physics, Vienna University of Technology, Wiedner Hauptstr. 8-10, 1040 Vienna, Austria amount of the $\gamma$ ' phase [1] that precipitates from the matrix $\gamma$ phase by adding essential solutes such as Al, $\mathrm{Ti}$, and $\mathrm{Nb}$. Interestingly, the partition behavior of different alloying elements in these two phases $\left(\gamma^{\prime}\right.$ and $\gamma$ ) is significantly different $[2,3]$. Understanding this behavior is very important for alloy designs $[4,5]$.

In the past, data on the elemental partition behavior in Nickel-based alloys have been experimentally determined [6-10]. In order to understand the mechanism of elemental partition behavior, researchers tried to reproduce these data using computational methods. For example, Saito [11] employed the Monte Carlo (MC) simulation method and successfully predicted the alloying element partitions in DMS4 Nickel-based alloys. Walston [10] used the neural network prediction method to predict the effect of addition of $\mathrm{Ru}$ and/or Co on the partition behavior of Re and obtained good agreement with experimental results. Liu [12] adopted the First-Principles (FP) calculation method and investigated the partition behavior of transition metal elements in Ni-based single crystal superalloys. However, in these methods, the neural network method is frequently mathematically indeterminate [13] and a large amount of experimental data are actually required for predictions; The MC and FP methods would consume a lot of computing resources to obtain satisfactory results [14]. Moreover, the FP method cannot get the change of element partition behavior caused by the concentration varying. In Nickelbased alloys, the elemental partition behavior is the results of a multi-component co-effect. For example, in the alloys EPM 16 and EPM 36, adding Ru [10] results in the elements $\mathrm{Cr}, \mathrm{W}, \mathrm{Mo}$, and Re partitioning more strongly in the $\gamma$ ' phase, and $\mathrm{Al}$ and Ta partitioning in the $\gamma$ phase. A similar phenomenon was observed by Kuo [15], who found that increasing the content of Ti in the Ni-19Al-xSi-yTi alloys increased the partition tendency of $\mathrm{Si}$ in the $\gamma$ matrix phase. Besides, the element partition behavior is also influenced by the concentration. For example, Mo and W concentrate more in the $\gamma$ phase with increasing the concentrations $[2,16]$. This phenomenon is difficult to simulate by the FP method.

Ordinarily, the partition behavior of an alloying element depends on the size of the chemical potential 
that is normally related to the compositions of the alloy at a certain temperature $T$ and pressure $P$. The effect of interaction between alloying elements on the chemical potential can be represented by the activity interaction parameters which are firstly proposed by Wagner [17]. In this work, we try to use these parameters to investigate the element partition behavior in Nickel-based alloys. However, in Nickel-based alloys, the relevant experimental data are rare. Thus, we have to resort to theoretical calculation methods. In theoretical calculations, two methods are deserved to be mentioned since in which, only few physical parameters of the constituent elements are needed. One is proposed by Ding $[18,19]$ and the other is developed by Ueno and Waseda [20, 21]. Ding [18, 19] established a model through combining the Miedema model and geometric model as well as other thermodynamic relations to predicts the activity interaction parameter and infinite dilution activity coefficient in any metal-based melts. Ueno and Waseda [20, 21] applied the pseudopotential formalism coupled with free energy of the hard sphere model to build up the interaction parameter model. The former we called as Ding method and the latter as Ueno method. However, the final formula of Ueno method [20, 21] still needs to be improved because it does not satisfy the Lupis reciprocal relationship [22], i.e., $\varepsilon_{i}^{j} \neq \varepsilon_{j}^{i}$. This problem does not exist in the Ding method $[18,19]$. Therefore, the Ding model $[18,19]$ was applied in this work.

\section{Calculation model}

In multi-component solutions, $\mathrm{k}-1-2-\ldots-\mathrm{n}, \mathrm{k}$ is solvent, a Taylor's expansion of $\ln \gamma_{1}$ as a function of the solutes is given by:

$$
\begin{aligned}
\ln \gamma_{1}= & \ln \gamma_{1}^{0}+\sum_{i=1}^{n} x_{i} \frac{\partial \ln \gamma_{1}}{\partial x_{i}}+\sum_{i=1}^{n}\left(\frac{1}{2} \frac{\partial^{2} \ln \gamma_{1}}{\partial x_{i}^{2}} x_{i}^{2}\right) \\
+ & \sum_{\substack{i=1 \\
j=2}}^{n}\left(\frac{\partial^{2} \ln \gamma_{1}}{\partial x_{i} \partial x_{j}} x_{i} x_{j}\right)+O\left(X^{3}\right) \\
j=2 &
\end{aligned}
$$

where $\gamma_{1}$ is the activity coefficient of component 1 , and $\gamma_{1}^{0}$ is the value at infinite dilution; the $x_{i}$ and $x_{j}$ are the mole fraction of solutes $i$ and $j$ respectively; $O\left(X^{3}\right)$ represents the residual term. And the activity interaction parameters are defined as follows:

$$
\begin{gathered}
\varepsilon_{1}^{j}=\left(\frac{\partial \ln \gamma_{1}}{\partial x_{j}}\right) \begin{array}{c}
x_{k} \rightarrow 1 \\
j=1,2, \cdots n
\end{array} \\
\rho_{1}^{1 j}=\left(\frac{\partial^{2} \ln \gamma_{1}}{\partial x_{1} \partial x_{j}}\right)_{\substack{x_{k} \rightarrow 1 \\
j=1,2, \cdots n}}
\end{gathered}
$$

$\varepsilon_{1}^{j}$ is the first-order activity interaction parameter of $j$ on 1 , $\rho_{1}^{1 j}$ is the second-order activity interaction parameter. According to the relationship between the activity coefficient $\gamma_{1}$, and the partial excess Gibbs free energy of component 1 in the mixing $G_{1}^{E}$, the $\ln \gamma_{1}^{0}, \varepsilon_{1}^{j}$, and $\rho_{1}^{1 j}$ can be rewritten as follows at a certain temperature $T$ and pressure $P$, respectively:

$$
\begin{aligned}
& \ln \gamma_{1}^{0}=\lim _{x_{1} \rightarrow 0} \frac{1}{R T}\left(G_{1}^{E}\right) \\
& \varepsilon_{1}^{j}=\frac{1}{R T}\left(\frac{\partial G_{1}^{E}}{\partial x_{j}}\right)_{x_{k} \rightarrow 1} \\
& \rho_{1}^{1 j}=\frac{1}{R T}\left(\frac{\partial^{2} G_{1}^{E}}{\partial x_{1} \partial x_{j}}\right)_{x_{k} \rightarrow 1}
\end{aligned}
$$

where $R$ is the gas constant and equal to $8.314 \mathrm{~J} / \mathrm{mol}$.

Therefore, if the partial excess Gibbs free energy of mixing $G_{1}^{E}$ is obtained, the above three parameters can be achieved. In the Ding's previous work [18, 19], models for calculating the $\ln \gamma_{1}^{0}, \varepsilon_{1}^{j}$, and $\rho_{1}^{1 j}$ have been established. They are:

$$
\begin{gathered}
\ln \gamma_{1}^{0}=\frac{1}{R T} f_{1 \mathrm{k}} \frac{1+u_{1}\left(\phi_{1}-\phi_{\mathrm{k}}\right)}{V_{\mathrm{k}}^{2 / 3}} \\
\varepsilon_{1}^{j}=\frac{1}{R T}(A-B-C) \\
\rho_{1}^{1 \mathrm{j}}=\frac{1}{R T}(A-B+C+D-E)
\end{gathered}
$$

where $A, B, C, D, E, f_{1 \mathrm{k}}, f_{1 \mathrm{j}}$ and $f_{\mathrm{jk}}$ are given as:

$$
\begin{aligned}
& A=f_{1 \mathrm{j}}\left[1+\mu_{1}\left(\phi_{1}-\phi_{\mathrm{j}}\right)\right] / V_{\mathrm{j}}^{2 / 3} \\
& B=f_{1 \mathrm{k}}\left[1+\mu_{1}\left(\phi_{1}-\phi_{\mathrm{k}}\right)\right] / V_{\mathrm{k}}^{2 / 3} \\
& C=f_{\mathrm{jk}}\left[1+\mu_{j}\left(\phi_{j}-\phi_{\mathrm{k}}\right)\right] / V_{\mathrm{k}}^{2 / 3}
\end{aligned}
$$




$$
\begin{aligned}
D= & f_{1 \mathrm{j}}\left\{\left[\left(4 \mu_{1}+2 \mu_{j}\right)\left(\phi_{j}-\phi_{1}\right)-2-2 \mu_{1} \mu_{j}\left(\phi_{j}-\phi_{1}\right)^{2}\right] / V_{j}^{2 / 3}\right. \\
& -2\left[1+\mu_{1}\left(\phi_{1}-\phi_{j}\right)\right]\left[V_{1}^{2 / 3}\left(1+\mu_{1}\left(\phi_{1}-\phi_{j}\right)\right)\right. \\
& \left.\left.+V_{j}^{2 / 3}\left(-1+\mu_{j}\left(\phi_{j}-\phi_{1}\right)\right)\right] /\left(V_{j}^{2 / 3}\right)^{2}\right\} \\
E= & f_{1 \mathrm{k}}\left\{\left[\left(4 \mu_{1}+2 \mu_{\mathrm{k}}\right)\left(\phi_{k}-\phi_{1}\right)-2-2 \mu_{1} \mu_{\mathrm{k}}\left(\phi_{k}-\phi_{1}\right)^{2}\right] / V_{k}^{2 / 3}\right. \\
& -2\left[1+\mu_{1}\left(\phi_{1}-\phi_{k}\right)\right]\left[V_{1}^{2 / 3}\left(1+\mu_{1}\left(\phi_{1}-\phi_{k}\right)\right)\right. \\
& \left.\left.+V_{k}^{2 / 3}\left(-1+\mu_{\mathrm{k}}\left(\phi_{k}-\phi_{1}\right)\right)\right] /\left(V_{k}^{2 / 3}\right)^{2}\right\} \\
f_{\mathrm{ij}}= & \frac{2 P V_{\mathrm{j}}^{2 / 3} V_{\mathrm{i}}^{2 / 3}}{\left(n_{W S}\right)_{\mathrm{i}}^{-1 / 3}+\left(n_{W S}\right)_{\mathrm{j}}^{-1 / 3}}\left[9.4\left(\left(n_{W S}\right)_{\mathrm{i}}^{1 / 3}-\left(n_{W S}\right)_{\mathrm{j}}^{1 / 3}\right)^{2}\right. \\
& \left.-\left(\phi_{\mathrm{i}}-\phi_{j}\right)^{2}-a\left(\frac{r}{P}\right)_{\mathrm{ij}}\right]
\end{aligned}
$$

where, $V_{i}$ is the molar volume of the corresponding component $i$ in $\mathrm{cm}^{3} / \mathrm{mol}$ at room temperature; $\left(n_{W S}\right)_{i}$ is the electron density of $i$ in electrons per $\left(0.529 \AA \AA^{3}\right)^{3} ; \phi_{i}$ is the electronegativity of $i$ in volts; $P, u_{\mathrm{i}} a$, and $r$ are the empirical constants and related to a specific composition. The values of above parameters for elements except for halides and chalcogenides are obtainable in Ref [23, 24], and the chalcogenides' parameters, used in this paper, are from the literature [25].

Equations (7) and (8) were successfully employed in Fe-based [18], Cu-based [26] and Co-based [19] melts by Ding. In this work, the infinite dilution activity coefficients of solutes and their activity interaction parameters in Nickel-based melts were calculated at $1873 \mathrm{~K}$. The calculation process is performed on our own developed software that is dedicated to calculating the activity coefficients and activity interaction parameters between components in metal-based melts.

\section{Results and discussion}

\section{The infinite dilution activity coefficient $\ln \gamma_{i}^{0}$ and solutes activity interaction parameter $\varepsilon_{i}^{j}$}

It should be noted that the activity coefficient relies on the choice of the standard state, and in our calculation a pure liquid substance is selected. However, the standard state used in literature or by other investigators may be different, hence implement the standard state conversion is required. According to the chemical potential of the component $i$ is independent on the standard state, the activity coefficient between a pure liquid standard state and a pure solid standard state for the same component (e.g. $\boldsymbol{i})$ can be converted mutually using: (in other standard states a similar equation to eq. (10) is used.)

$$
\ln \gamma_{i}^{\mathrm{L}}=\ln \gamma_{i}^{\mathrm{S}}-\frac{u_{i}^{0 \mathrm{~L}}-u_{i}^{\mathrm{OS}}}{R T}
$$

where, the superscripts $\mathrm{L}$ and $\mathrm{S}$ represent the pure liquid and the pure solid, respectively; $R$ and $T$ are the gas constant and the absolute temperature, respectively; the value of $u_{i}^{0 L}-u_{i}^{0 S}$ is equal to the change of the Gibbs free energy for 1 mole pure component $\boldsymbol{i}$ from solid to liquid at the temperature $\mathrm{T}$. In addition, some literature values are given at different temperatures, this can be transformed to at other temperatures by the following relation:

$$
\ln \gamma_{T_{1}}=\frac{T_{2}}{T_{1}} \ln \gamma_{T_{2}}
$$

\begin{tabular}{|c|c|c|c|c|c|}
\hline \multirow[t]{2}{*}{$i$} & \multicolumn{2}{|c|}{$\ln \gamma_{i}^{0}$} & \multirow[t]{2}{*}{$i$} & \multicolumn{2}{|c|}{$\ln \gamma_{i}^{0}$} \\
\hline & This work & Literature & & This work & Literature \\
\hline B & -5.47 & $-4.71[27]$ & Mo & -2.09 & $-1.53[28]$ \\
\hline C & -8.35 & $-5.83[28]$ & $\mathrm{Ru}$ & 0.14 & \\
\hline $\mathrm{N}$ & -15.96 & & $\mathrm{Rh}$ & -0.26 & \\
\hline 0 & -19.05 & $-56.29[28]$ & $\mathrm{Pd}$ & -0.02 & $0.01[28]$ \\
\hline $\mathrm{Al}$ & -6.20 & $-8.52[28]$ & $\mathrm{Cd}$ & 0.57 & \\
\hline $\mathrm{Si}$ & -6.30 & $-9.21[28]$ & In & 0.54 & $0.58[28]$ \\
\hline$P$ & -9.68 & & Sn & -1.35 & $-0.89[28]$ \\
\hline$S$ & -6.50 & & $\mathrm{Sb}$ & -0.46 & $0.25[28]$ \\
\hline Sc & -12.33 & & $\mathrm{Hf}$ & -13.11 & \\
\hline $\mathrm{Ti}$ & -9.87 & $-8.50[28]$ & Ta & -8.52 & $-7.15[28]$ \\
\hline $\mathrm{Cr}$ & -1.73 & $-1.40[27]$ & W & -0.91 & $-0.25[28]$ \\
\hline $\mathrm{Mn}$ & -2.12 & $-1.75[27]$ & $\operatorname{Re}$ & 0.66 & \\
\hline $\mathrm{Fe}$ & -0.41 & $-1.02[28]$ & Os & 0.37 & \\
\hline Co & -0.06 & $-0.05[28]$ & Ir & -0.43 & \\
\hline $\mathrm{Cu}$ & 0.91 & 1.06 [29] & Pt & -1.40 & \\
\hline Ga & -4.42 & & Y & -11.09 & \\
\hline $\mathrm{Ge}$ & -3.27 & $-2.04[28]$ & $\mathrm{Zr}$ & -13.80 & $-13.02[28]$ \\
\hline $\mathrm{Nb}$ & -8.71 & $-7.34[27]$ & V & -4.83 & $-4.71[28]$ \\
\hline
\end{tabular}

Table 1 lists the comparison of the calculated results and the literature/experimental values for the logarithm of solutes infinite dilution activity coefficients $\left(\ln \gamma_{i}^{0}\right)$. It's easy to find that a good agreement is achieved. Only $\ln \gamma_{0}^{0}$ has a relatively large deviation, this is maybe

Table 1: Calculated results for $\ln \gamma_{i}^{0}$ of solute elements at $1873 \mathrm{~K}$ in Nickel-based melts and the corresponding literature values. 
caused by that: (1) a strong interaction exists between Oxygen and Nickel atoms, and (2) only slight rearrangements of the Nickel atoms are necessary when Oxygen atoms enter into liquid Nickel matrix as quasi-interstitials since the radius of Oxygen atom is smaller than Nickel atom. In the Ding's model $[18,19]$, the second point is neglected. For the elements Pd and Sb, the signs of the calculated values are inconsistent with the data given in Ref [28]. However, the difference of their absolute values is very small.

Table 2 lists the comparison of the calculated results and literature/experimental values for the first-order activity interaction parameters $\varepsilon_{i}^{j}$ of $\boldsymbol{j}$ on $\boldsymbol{i}$ in Nickelbased melts at 1873K. Basically, the first-order activity interaction parameters of $\boldsymbol{j}$ on $\boldsymbol{i}$ and $\boldsymbol{i}$ on $\boldsymbol{j}$ are identical in the same matrix since it satisfies the reciprocal relationship which given by Lups and Elliott [22], i.e.

Table 2: Calculated results for $\varepsilon_{i}^{j}$ in Nickel-based melts at $1873 \mathrm{~K}$ and the corresponding values from literatures.

\begin{tabular}{|c|c|c|c|c|c|c|c|}
\hline \multirow[t]{2}{*}{$i$} & \multirow[t]{2}{*}{$j$} & \multicolumn{2}{|c|}{$\varepsilon_{i}^{j}$} & \multirow[t]{2}{*}{$i$} & \multirow[t]{2}{*}{$j$} & \multicolumn{2}{|c|}{$\varepsilon_{i}^{j}$} \\
\hline & & This work & Literature & & & This work & Literature \\
\hline Al & $\mathrm{Al}$ & 14.3 & 9.0 & $\mathrm{Cr}$ & $\mathrm{Cr}$ & 1.8 & 3.5 \\
\hline $\mathrm{Al}$ & $\mathrm{N}$ & 2.3 & 0.54 & $\mathrm{Cr}$ & $\mathrm{Si}$ & 2.5 & \\
\hline $\mathrm{Au}$ & $\mathrm{Au}$ & -5.7 & -0.2 & $\mathrm{Cr}$ & Mo & 4.5 & \\
\hline $\mathrm{Ce}$ & $\mathrm{N}$ & -55.6 & -304.0 & $\mathrm{Cr}$ & W & 3.4 & \\
\hline Co & Co & 0.1 & 0 & $\mathrm{Cr}$ & $\operatorname{Re}$ & 0.1 & \\
\hline Co & $\mathrm{N}$ & -1.2 & -1.3 & $\mathrm{Cr}$ & 0 & -7.5 & $-25.0[30]$ \\
\hline $\mathrm{Cu}$ & $\mathrm{Cu}$ & -1.7 & -1.9 & Mo & $\mathrm{N}$ & -5.4 & -16.0 \\
\hline $\mathrm{Fe}$ & $\mathrm{Fe}$ & 0.8 & 3.0 & Mo & Mo & 5.1 & \\
\hline $\mathrm{Fe}$ & $\mathrm{N}$ & -3.0 & -4.3 & w & W & 2.3 & \\
\hline $\mathrm{N}$ & $\mathrm{N}$ & 29.4 & 0.8 & W & $\mathrm{N}$ & -4.1 & -189.0 \\
\hline 0 & 0 & 33.3 & 0.7 & W & $\mathrm{Ta}$ & 7.5 & \\
\hline $\mathrm{Si}$ & $\mathrm{Si}$ & 14.5 & 13.0 & $\mathrm{Zr}$ & $\mathrm{N}$ & -52.7 & -86.0 \\
\hline$S$ & $S$ & 17.4 & -3.0 & $\mathrm{Ru}$ & $\mathrm{Cr}$ & -1.2 & \\
\hline $\mathrm{Ti}$ & $\mathrm{Ti}$ & 24.4 & 15.2 [31] & $\mathrm{Ru}$ & Mo & -1.8 & \\
\hline $\mathrm{Ti}$ & $\mathrm{Si}$ & 3.16 & & $\mathrm{Ru}$ & $\mathrm{Re}$ & -1.5 & \\
\hline $\mathrm{Ti}$ & $\mathrm{N}$ & -37.0 & -37.0 & $\mathrm{Ru}$ & w & -1.8 & \\
\hline $\mathrm{Cr}$ & $\mathrm{Fe}$ & 1.4 & 2.2 & $\mathrm{Ru}$ & $\mathrm{Al}$ & 0.7 & \\
\hline $\mathrm{Cr}$ & $\mathrm{N}$ & -5.9 & -22.0 & $\mathrm{Ru}$ & $\mathrm{Ta}$ & -2.1 & \\
\hline $\mathrm{Cr}$ & $\mathrm{Ti}$ & 9.5 & 11.3 & & & & \\
\hline
\end{tabular}

Notes: the literature values are from the Ref [27]. except for otherwise indicated.

$$
\varepsilon_{i}^{j}=\varepsilon_{j}^{i}
$$

It's easy to find from Table 2 that the calculation results are in good agreement with the literature values. Most of the data are within tolerable deviations except for some ones such as $\varepsilon_{W}^{N}$, $\varepsilon_{O}^{O}$, and $\varepsilon_{C e}^{N}$, that have relatively large deviations. A common feature of these data is the calculated values are larger than the values given in literature. More specifically, when the interaction is attractive $\left(\varepsilon_{i}^{j}<0\right)$, the calculated value shows a weaker attraction than the literature one; when the interaction is rejective $\left(\varepsilon_{i}^{j}>0\right)$, the calculated value shows a stronger rejection than the literature one. It may be due to that no rearrangement of Nickel atoms in the matrix occurs when an atom with a small size enters into. On the other hand, the small solute atoms could be compressed by the matrix atoms on the lattices, which leads to a negative contribution to the activity interaction parameter. However, this extra contribution is neglected in the Ding's model [18, 19]. Nevertheless, the calculated results are still encouraging.

\section{The element partition behavior in the $\gamma^{\prime}$ and $\gamma$-phase}

Figure 1 highlights the preferential partition behavior of elements into the $\gamma$, or $\gamma$ phase in Nickel-based alloys. It shows that elements located at both ends of the periodic table have preferential partitions in the $\gamma$ ' phase, while at the middle region are preferentially distributed in the $\gamma$ phase. Pollock [1] has used the atomic size to distinguish the partition behavior of elements in the $\gamma^{\prime}$ and $\gamma$ phases and obtained that, elements with similar atomic size to Nickel are preferentially distributed into the $\gamma$ phase. However, this is obviously insufficient as the preferential partition behavior of elements in different phases depends on its relative magnitude of chemical potential in each phase.

In Nickel-based alloys, the $\gamma^{\prime}$ and $\gamma$ phases are the main constituent phases with different structures. The $\gamma$ phase $[1,35]$ is a solid solution with a face-centers cubic lattice and a random distribution of the different species of atoms, the $\gamma^{\prime}$ phase [1] is intermetallic with nominal compositions Ni3X ( $\mathrm{X}$ is Al, Ti, Nb, Ta, Hf etc.). Therefore, there must be a strong attraction between $\mathrm{X}$ and $\mathrm{Ni}$, or exactly, X can be firmly captured by Ni in Nickel-based alloys. To some degree, this attraction can be understood from the perspective of the infinite dilution activity coefficient, since

$$
\begin{gathered}
\ln \gamma_{i}^{0}=\lim _{x_{i} \rightarrow 0}\left(\ln \gamma_{i}\right)=\frac{1}{R T} \lim _{x_{i} \rightarrow 0}\left(u_{i}^{E}\right) \\
u_{i}^{E}=u_{i}^{r}-u_{i}^{i d}
\end{gathered}
$$




\begin{tabular}{|c|c|c|c|c|c|c|c|c|c|c|}
\hline Y & $\mathrm{Al}$ & & & & & & & & B & $\mathrm{Si}$ \\
\hline $\mathrm{Ti}$ & V & $\mathrm{Cr}$ & $\mathrm{Mn}$ & $\mathrm{Fe}$ & Co & & $\mathrm{Cu}$ & $\mathrm{Zn}$ & $\mathrm{Ga}$ & $\mathrm{Ge}$ \\
\hline $\mathrm{Zr}$ & $\mathrm{Nb}$ & Mo & $\mathrm{Tc}$ & $\mathrm{Ru}$ & $\mathrm{Rh}$ & $\mathrm{Pd}$ & & $\mathrm{Cd}$ & In & $\mathrm{Sn}$ \\
\hline $\mathrm{Hf}$ & $\mathrm{Ta}$ & W & $\operatorname{Re}$ & Os & Ir & $\mathrm{Pt}$ & & & & $\mathrm{Pb}$ \\
\hline
\end{tabular}

Figure 1: Alloying elements present in Nickel-based alloys (data adapted from Ref [3, 32-34]).

where $u_{i}^{E}$ is the excess chemical potential of component $\boldsymbol{i}$ in solution and is defined as the difference between the chemical potential of component $\boldsymbol{i}$ at a real state and an ideal state under the same conditions. Therefore, if $\ln \gamma_{i}^{0}$ approaches to zero, the mixture of the component $\boldsymbol{i}$ and the solvent/matrix is close to ideal; and if the $\ln \gamma_{i}^{0} \gg 0$, the atom of the element $\boldsymbol{i}$ may be rejected from the solvent/matrix due to the chemical potential of the element $\boldsymbol{i}$ will be increased after mixing; if the $\ln \gamma_{i}^{0} \ll 0$, the atom of the element $\boldsymbol{i}$ would be attracted by the solvent/ matrix strongly so that an ordered intermetallic compound can be formed.

Figure 2 plots the logarithm of the infinite dilution activity coefficient $\left(\ln \gamma_{i}^{0}\right)$ of different elements in Nickelbased alloys at $1873 \mathrm{~K}$. Combining Figure 1, it's easy to know that $\ln \gamma_{i}^{0}$ of almost all $\gamma$-formed elements is close to zero (except for $\mathrm{Pb}$, the $\ln \gamma_{\mathrm{Pb}}^{0}$ is relatively far from zero axes with a positive sign), while for the $\gamma^{\prime}$-formed elements, the $\ln \gamma_{i}^{0}$ is apparently more negative than the former. In this work, we only compared the data under $1873 \mathrm{~K}$, and when the temperature decreases, the difference becomes more obvious. Therefore, the preferential partition behavior of element $\boldsymbol{i}$ in the $\gamma^{\prime}$ and $\gamma$ phases can be well distinguished by its logarithm of the infinite dilution activity coefficients $\left(\ln \gamma_{i}^{0}\right)$.
In addition, the partition behavior of element $i$ in the $\gamma$, and $\gamma$ phases is also affected by the third elements $\boldsymbol{j}$ and its concentration in Nickel-based alloys [5, 9, 36]. This phenomenon have been investigated by many researchers $[10,13,37]$ through different methods. However, these methods are not light and convenient enough, sometimes even they are not able to explain the effects caused by the changes of concentration. According to the definition of activity interaction parameters, $\varepsilon_{i}^{j}$ and $\rho_{i}^{i j}$ can be rewritten as follows:

$$
\begin{gathered}
\varepsilon_{i}^{j}=\frac{1}{R T}\left(\frac{\partial u_{i}^{E}}{\partial x_{j}}\right)_{x_{k} \rightarrow 1} \\
\rho_{i}^{i j}=\frac{1}{R T}\left(\frac{\partial^{2} u_{i}^{E}}{\partial x_{i} \partial x_{j}}\right)_{x_{k} \rightarrow 1}
\end{gathered}
$$

hence, the $\varepsilon_{i}^{j}$ represents the fact that the effect of $\boldsymbol{j}$ on the chemical potential of $\boldsymbol{i}$ in the solution at infinite dilution; and the $\rho_{i}^{i j}$ represents that the co-effect of $\boldsymbol{i}$ and $\boldsymbol{j}$ on the chemical potential of $\boldsymbol{i}$ in the solution. And their signs imply that whether the chemical potential of $\boldsymbol{i}$ will increase or decrease after $\boldsymbol{j}$ is added. The significance of this effect is typically related to its value. Generally, the

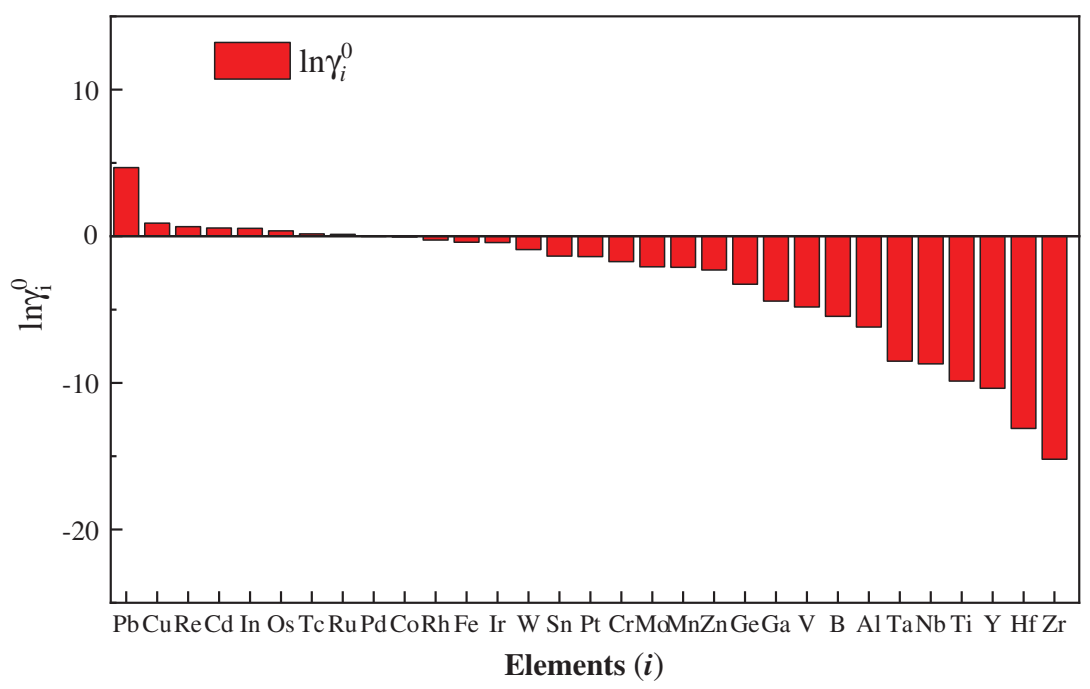

Figure 2: The infinite dilution activity coefficients in Nickel-based alloys at $1873 \mathrm{~K}$. 
greater the chemical potential of the element $\boldsymbol{i}$ in one phase, the greater the probability it escapes from this phase. Therefore, if the sign of $\varepsilon_{i}^{j}$ or $\rho_{i}^{i j}$ is positive, adding $\boldsymbol{j}$ or increasing $\boldsymbol{j}$ 's concentration in the solution increases the probability of $\boldsymbol{i}$ escaping from the matrix phase, while negative implies the element $\boldsymbol{i}$ will be promoted to partition in the matrix phase.

Table 3 lists the change of partition behavior of element $\boldsymbol{i}$ caused by adding a third element $\boldsymbol{j}$. Elements in the second and third columns in Table 3 represent that their partition behaviors are altered to the corresponding phase after adding the element in the first column. For example, at the second row, adding Ru or increasing the concentration of $\mathrm{Ru}$ in Nickel-based alloys promotes the $\mathrm{Ta}$ and $\mathrm{Al}$ atoms to partition preferentially into the $\gamma$ phase, while $\mathrm{Cr}$, Mo, $\mathrm{W}$ and Re to the $\gamma$ '-phase.

Table 3: The effect of adding/increasing $j$ on the partition behavior of other elements in Nickelbased alloys.

\begin{tabular}{llrr}
\hline j & $\gamma$-phase & $\gamma^{\prime}$-phase & References \\
\hline Ru & Ta, Al & Cr, Mo, W, Re & {$[5,13]$} \\
Cr & Cr, W, Mo & & {$[33,36]$} \\
Ti & Si & {$[15]$} \\
Mo & Mo & {$[6,7,38]$} \\
Ta & W & {$[8]$} \\
W & W & {$[6,7,38]$} \\
\hline
\end{tabular}

Figure 3 plots the first-order activity interaction parameter $\varepsilon_{i}^{j}$ for those elements from Table 3, where $\boldsymbol{j}$ and $\boldsymbol{i}$ are from the first column and second or third column in

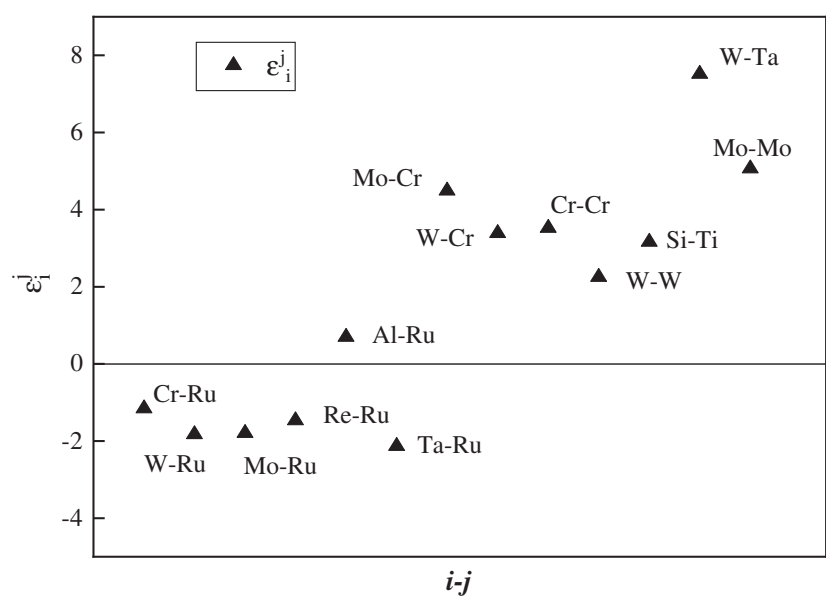

Figure 3: The first-order activity interaction parameter $\varepsilon_{i}^{j}$ in Nickelbased alloys at $1873 \mathrm{~K}$.
Table 3, respectively. Adding Ru promotes both Ta and Al to partition in the $\gamma$ phase, however, in Figure $3, \varepsilon_{T a}^{R u}$ and $\varepsilon_{A l}^{R u}$ are located at the two side of the zero line. This implies that the change of the partition behavior of the element $\boldsymbol{i}$ that it caused by the third element $\boldsymbol{j}$ or $\boldsymbol{j}$ 's concentration in Nickel-based alloys cannot be well separated by the sign of their first-order activity interaction parameter $\varepsilon_{i}^{j}$. Figure 4 plots the second-order activity interaction parameters $\rho_{i}^{i j}$ for these elements in Nickelbased alloys. Amazingly, the second-order activity interaction parameters $\rho_{i}^{i j}$ are effectively divided into two sides of the zero line in Figure 4, according to the difference of partition behavior for $\boldsymbol{i}$ in the $\gamma^{\prime}$ or $\gamma$ phase that caused by adding $\boldsymbol{j}$ in Nickel-based alloys, i.e. when $\rho_{i}^{i j}<0$, adding $\boldsymbol{j}$ makes $\boldsymbol{i}$ more readily to partition in the $\gamma$ phase, when $\rho_{i}^{i j}>0$, adding $\boldsymbol{j}$ promotes $\boldsymbol{i}$ to partition in the $\gamma$ ' phase. This indicates that the effect of adding $\boldsymbol{j}$ on the change of the partition behavior of element $\boldsymbol{i}$ can be well distinguished by the sign of $\rho_{i}^{i j}$. Of course, element eventually partition in different phases depends on its relative magnitude of chemical potential in each phase as well as the process of kinetics. In this work, we just tried to discuss the trends of this partition behavior for alloying elements at equilibrium from the thermodynamics point of view.

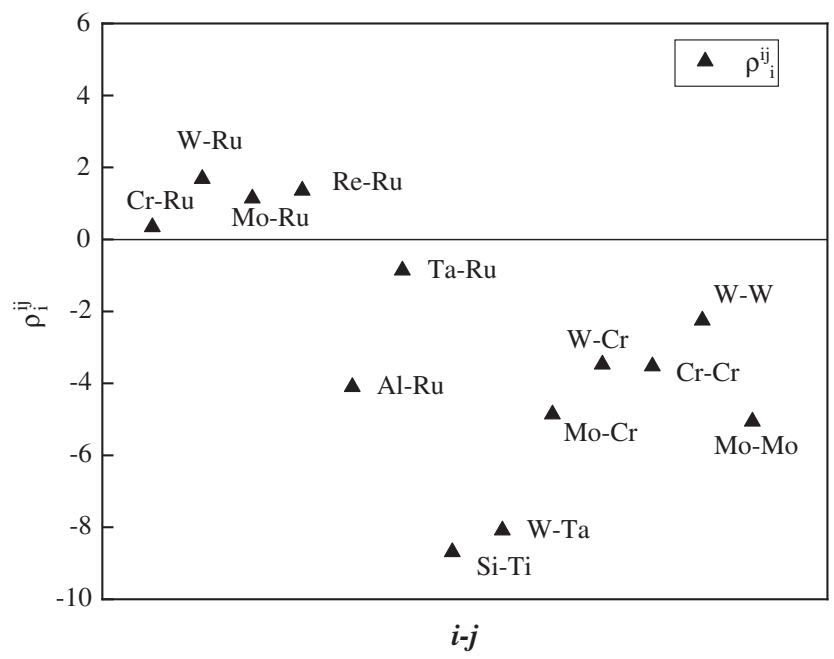

Figure 4: The second-order activity interaction parameter $\rho_{i}^{i j}$ in Nickel-based alloys at 1873K.

\section{Conclusions}

The activity interaction parameters and infinite dilution activity coefficients have been calculated by the Ding's model $[18,19]$ in Nickel-based alloys at 1873K. The partition behavior of typically alloying elements (such as Ti, 
Cr, Mo, W, and Re.) in Nickel-based alloys into the $\gamma^{\prime}$ or $\gamma$ phase was investigated by using the infinite dilution activity coefficient and activity interaction parameter. The conclusions are obtained as follows:

1) A good agreement is achieved between the calculated results and the literature values for solutes infinite dilution activity coefficients and their activity interaction parameters in Nickel-based alloys at 1873K.

2) The preferential partition behavior of elements in Nickel-based alloys in the $\gamma^{\prime}$ or $\gamma$ phase is related to the infinite dilution activity coefficient $\left(\ln \gamma_{i}^{0}\right)$. When $\ln \gamma_{i}^{0}$ is closer to zero, the element $\boldsymbol{i}$ is easier to partition to the $\gamma$ phase, when it is more negative ( $\left.\ln \gamma_{i}^{0} \ll 0\right)$, it is more possible to form the $\gamma^{\prime}$ phase.

3) The change of partition behavior of element $\boldsymbol{i}$ arising from the third element $\boldsymbol{j}$ or $\boldsymbol{j}$ 's concentration in Nickel-based alloys can be distinguished by the sign of the second-order activity interaction parameter $\rho_{i}^{i j}$. The first-order activity interaction parameter $\varepsilon_{i}^{j}$ is insufficient to separate it.

Acknowledgements: This work was supported by the National Key R\&D Program of China (2017YFB0603801).

\section{References}

[1] T.M. Pollock and S. Tin, J. Propul. Power., 22 (2006) 361-374.

[2] M. Enomoto and H. Harada, Metall. Trans. A, 20 (1989) 649-664.

[3] C.C. Jia, K. Ishida and T. Nishizawa, Metall. Mater. Trans. A, 25 (1994) 473-485.

[4] M. Detrois, S. Antonov, R.C. Helmink, et al., JOM, 66 (2014) 2478-2485.

[5] A. Heckl, S. Neumeier, S. Cenanovic, et al., Acta Mater., 59 (2011) 6563-6573.

[6] R.C. Reed, A.C. Yeh, S. Tin, et al., Scr. Mater., 51 (2004) 327-331.

[7] C.Y. Cui, M. Osawa, A. Sato, et al., Metall. Mater. Trans. A, 37 (2006) 355-360.

[8] Y. Amouyal, Z. Mao and D.N. Seidman, Acta Mater., 58 (2010) 5898-5911.

[9] L.Y. Kuo, Y.J. Chang and A.C. Yeh, Metall. Mater. Trans. A, 48a (2017) 3920-3926.

[10] S. Walston, A. Cetel, R. Mackay, et al., Proceedings of the10th International Symposium on Superalloys, Septemper 19-23, 2004, Warrendale, PA, (2004), pp. 15-24.
[11] Y. Saito and H. Harada, Mat. Sci. Eng. a-Struct., 223 (1997) 1-9.

[12] S. Liu, M. Wen, Z. Li, et al., Mater. Des., 130 (2017) 157-165.

[13] W. Sha and K.L. Edwards, Mater. Des., 28 (2007) 1747-1752.

[14] S. Shi, J. Xu, Y. Cui, et al., Sci. Tech. Rev., 33 (2015) 20-30.

[15] L.-Y. Kuo, Y.-J. Chang and A.-C. Yeh, Metall. Mater. Trans. A, 48 (2017) 3920-3926.

[16] W.T. Loomis, J.W. Freeman and D.L. Sponseller, Metall. Mater. Trans. B, 3 (1972) 989-1000.

[17] C. Wagner, Thermodynamics of Alloys, Addison-Wesley Press, Cambridge, Mass. (1952).

[18] X.Y. Ding, P. Fan and Q. Han, Acta Metall. Sin., 30 (1994) 49-60.

[19] X.Y. Ding, W. Wang and P. Fan, Metall. Mater. Trans. B, 30 (1999) 271-277.

[20] Y. Waseda, High Temp. Mater. Processes, 31 (2012) 203-208.

[21] S. Ueno, Y. Waseda, K.T. Jacob, et al., Process Metallurgy, 59 (1988) 474-483.

[22] C.H.P. Lupis and J.F. Elliott, Acta Metall., 14 (1966) 529-538.

[23] A.K. Niessen, A.R. Miedema, F.R. De Boer, et al., Physica B + C, 151 (1988) 401-432.

[24] A.R. Miedema, P.F. De Châtel and F.R. De Boer, Physica B + C, 100 (1980) 1-28.

[25] J. Neuhausen and B. Eichler, Extension of Mediema's Macroscopic Atom Model to the Elements of Group 16 (0, S, Se, Te, Po), PSI Report No. 03-13, 2003.

[26] X.Y. Ding, P. Fan and L.H. Luo, Alloy Melts Thermodynamic Model: Predictionand Software Development, Northeastern University Press, Shenyang (1998).

[27] G.K. Sigworth, J.F. Elliott, G. Vaughn, et al., Can. Metall. Q., 16 (2013) 104-110.

[28] T. Tanaka, N. Imai, A. Kiyose, et al., Z. Metallkd., 82 (1991) 836-840.

[29] S. An Mey, Calphad, 16 (1992) 255-260.

[30] M. Heinz, K. Koch and D. Janke, Steel Res., 60 (1989) 246-254.

[31] A.A. Aleksandrov, V.Y. Dashevskii and L.I. Leont'ev, Steel Trans., 46 (2016) 479-483.

[32] T.M. Pollock and R.D. Field, Chapter 63 in Dislocations in Solids edited by F.R.N. Nabarro and M.S. Duesbery, Elsevier (2002), pp. 547-618.

[33] S. Yoshitake, V. Narayan, H. Harada, et al., ISIJ Int., 38 (1998) 495-502.

[34] A. Chiba, S. Hanada and S. Watanabe, Scr. Metall. Mater., 25 (1991) 1053-1057.

[35] E.O. Ezugwu, Z.M. Wang and A.R. Machado, J. Mater. Process. Technol., 86 (1999) 1-16.

[36] L.J. Carroll, Q. Feng, J.F. Mansfield, et al., Mat. Sci. Eng. a-Struct., 457 (2007) 292-299.

[37] S.H. Liu, M.R. Wen, Z. Li, et al., Mater. Des., 130 (2017) 157-165.

[38] M. Enomoto, H. Harada and M. Yamazaki, Calphad, 15 (1991) 143-158. 